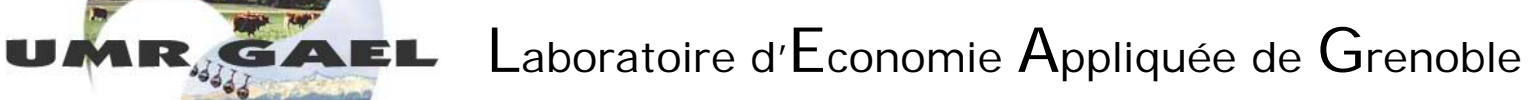
ainte

\title{
VARIETY AND THE EVOLUTION OF REFINERY PROCESSING
}

Phuong NGUYEN ; Pier-Paolo SAVIOTTI ; Michel TROMMETTER ; Bernard BOURGEOIS

Working Paper ; 2004-28

- October 2004 -

Institut National de la Recherche Agronomique - Université Pierre Mendès France Unité Mixte de Recherche 1215

Domaine Universitaire - BP 47 - 38040 GRENOBLE Cedex 9

Tél. : 33 (0) 476825439 - Fax : 33 (0) 476825455

E-mail : vertier@grenoble.inra.fr - http://www.grenoble.inra.fr 
VARIETY AND THE EVOLUTION OF REFINERY PROCESSING

\author{
Phuong NGUYEN*, Pier-Paolo SAVIOTTI**1 ${ }^{*}$, Michel TROMMETTER** and Bernard BOURGEOIS* \\ * CNRS / IEPE, Université Pierre Mendès-France, BP 47, 38040 Grenoble Cedex 9, France \\ ** INRA /GAEL, Université Pierre Mendès-France, BP 47, 38040 Grenoble Cedex 9, France
}

\begin{abstract}
Evolutionary theories of economic development stress the role of variety as both a determinant and a result of growth. In this paper we develop a measure of variety, based on Weitzman's maximum likelihood procedure. This measure is based on the distance between products, and indicates the degree of differentiation of a product population. We propose a generic method, which permits to regroup the products with very similar characteristics values before choosing randomly the product models to be used to calculate Weitzman's measure. We apply the variety measure to process characteristics of oil refining. The results obtained for this technology show classic evolutionary specialization patterns that can be understood on the basis of niche theory. Here the changes in variety are related to changes in the range of the services the technology considered can deliver, range which plays a role similar to that of the size of the habitat of a biological species.
\end{abstract}

Keywords : Technological evolution, refinery processes, variety, niche theory, Weitzman measure.

JEL classification : L15 -L93 -O3

\title{
1) INTRODUCTION AND GENERAL BACKGROUND.
}

\section{1) INTRODUCTION.}

The concept of variety has been playing a considerable role in theories of consumption and welfare (Lancaster, 1975, Dixit Stiglitz, 1977) and, increasingly, of economic growth (see for example Romer, 1987,1990; Bils et al 2001; Funke, Ruhwedel, 2001a, 2001b). In this paper variety is defined as the number of objects, activities and actors required to describe the economic system. In previous work by one of us the hypotheses that (i) variety growth is a necessary requirement for the continuation of long term economic development and that (ii) variety growth, leading to new sectors, and productivity growth in pre-existing sectors are complementary phenomena (Saviotti, 1996) were formulated. To test these, or any other hypotheses, measurements of variety are required. In this paper we present the results of our measurements of variety for the petroleum refining industry during the period 1932-1998, based on the Weitzman technique. Our previous measurements of variety were all carried out for product technologies. This is the first case in which we measure variety for a process technology.

In what follows we first analyse in greater detail the concept of variety (section 1.2), then we describe the evolution of the industry of petroleum refining (section 1.3), subsequently we present the methods used and the results obtained (section 4). Finally we provide an interpretation for these results and some conclusions (Section 5).

\section{2) THE CONCEPT OF VARIETY}

In the economic literature, variety is used to describe differentiation within a given product group. The type of problems in which the concept of variety is used, such as the optimum level of product differentiation, are both static and conceived at a low level of aggregation, i.e., a given product class. By contrast, an evolutionary theory deals with the interplay between variety-creation and market selection by focusing on changes in variety over time. In this context, the relevant level of aggregation is necessarily higher than has traditionally been the case in the economics literature, since its aim is to account for qualitative change, i.e., the emergence of new product classes. In biology, the concept of diversity is defined as the number of species existing in a given habitat. This concept bears a considerable similarity to that of variety we will develop here, though the differences between the two disciplines must be borne in mind. Thus, the concept of variety used in this paper is intermediate between the one traditionally used in economics and the one used in biology.

In the past our measures of variety have been performed on product technologies. These measures were based on a twin characteristics representation of products (Saviotti, Metcalfe, 1984). Each product technology is

\footnotetext{
${ }^{1}$ Corresponding author. Email address: saviotti@grenoble.inra.fr (P.Saviotti)
} 
represented by means of two sets of characteristics, describing the internal structure of the technology (technical characteristics) and the services performed for its users (service characteristics) respectively. The two sets of characteristics are related since technical characteristics are modified in order to provide the required service characteristics (Fig. 1). For example, a faster and bigger car requires a more powerful engine.

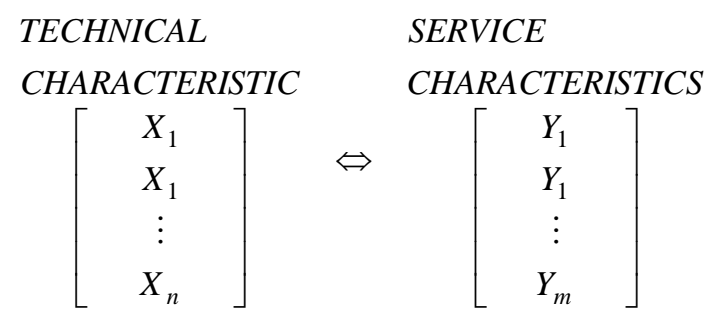

Fig. 1. The twin characteristics representation of a product model. The double arrow between technical and service characteristics of a product represents the pattern of imaging.

Typically heterogeneous multicharacteristics products are highly differentiated. Within an industrial sector each producer offers models of the same products which are somewhat different from those of its competitors. If we concentrate for the time being only on service characteristics, each product model will be represented by a point in a multidimensional space with a number of dimensions equal to the number of its service characteristics. The set of product models present in an industrials sector will then be constituted by a cloud of points, representing the population of models produced within a given sector, which will be more or less dense depending on the similarity of the product models of the different producers. We can expect the variety of an economic system to depend on the number of distinguishable technological/product populations that it contains and on the extent of internal differentiation of each population. Specifically, variety can be expected to increase when the number of distinguishable populations grows and when the extent of internal differentiation of each population increases.

A characteristics approach to the study of product technologies can shed light on a number of important aspects of the evolution of industries. For example, we can rank different producers in terms of their closeness to the existing technological frontier and analyse their strategies (Gibbons et al 1982), identify trajectories for technological development (Saviotti, Bowman, 1984; Saviotti Trickett, 1992), study the changing competitive conditions in particular industries (Saviotti, 1985), and measure the variety of product technologies (Frenken et al, 1999). In the present paper we measure for the first time the variety of a process technology. Each process is here represented by a set of values of process characteristics, and thus corresponds to a point in a multidimensional space. As in the case of product technologies a population of processes will be represented by a cloud of points in characteristics space.

For both product and process technologies we can expect that some evolutionary trends will take place. For example, we can expect that the centre of both product and process populations will move away from the origin of the axes during the evolution of these technologies. Likewise, we can expect the number of process populations to increase as a result of either specialization or of the creation of completely new products or processes. In the latter case new dimensions of characteristics space would be created.

The twin characteristics approach allows us to distinguish radical from incremental innovations. A radical innovation, giving rise to a qualitatively different product or service, will be represented by a completely different set of characteristics with respect to any previous technology. In order to be radical an innovation must (i) be based on qualitatively different technical characteristics, (ii) provide qualitatively different services or have both of the two previous features. On the other hand, an incremental innovation would consist only of quantitative variations of existing characteristics. Even this definition is not perfect because a new technology can share some characteristics with pre-existing ones and contain some qualitatively new characteristics. In this case the distinction between radical and incremental innovations would depend on the relative "weight" of the new characteristics, for example by the contribution of the new characteristics to either costs or to services performed. Nevertheless, in spite of its limitations this definition reduces the extent of subjectivity inherent in the distinction radical/incremental innovation.

The evolution of product or process populations and its expected impact on variety can be analysed also by means of a variant of niche theory, a theory of biological origin. In economic terms a niche can be considered the precursor of a market. In the niche new products and services are tried and only if they succeed and become widely adopted the niche is transformed into a market. The niche can also be seen from the viewpoint of populations of products or of firms. In the niche the products are few and not yet standardized. The firms producing in the niche are few and tend to behave in an entrepreneurial way. The niche itself is created in order 
to obtain a temporary monopoly. We can expect a two way relationship between niches and markets. If the products and services creating the niche are successful, the niche will grow and become a market. On the other hand, the larger the market, the greater the number of new niches that can be created within it. According to a model of technological evolution based on replicator dynamics (Saviotti and Mani, 1995; Saviotti, 1996) the rate of creation of new technological populations is proportional to the volume in service characteristics space of a pre-existing population. The volume in service characteristics space is a measure of the scope of the technology, that is, of the range of services it can perform, or equivalently, of the size of its market. We can expect the scope for specialization of a technology to increase with the range of services it can provide, or correspondingly, with the size of its market. The faster the rate of growth of a given market, the higher the probability that niches can be created within it. Niches can be formed both by the emergence of a completely new product, entailing the creation of new dimensions in characteristics space, or by the specialisation of existing technologies, thus creating new populations within existing dimensions of characteristics space. Both of these processes increase the division of labour by raising the number of distinguishable types of outputs and of the corresponding competencies. Increasing the number of niches can be expected to raise output variety.

This result corresponds to the prediction by niche theory in biology, according to which the number of niches that can be created in a given habitat is proportional to the size of the habitat (May 1973). Of course, we do not expect niche theory to apply unchanged to an economic environment. However, the idea that the number of niches is proportional to the range of services performed seems rather intuitive. Indeed, the range of services provides us with a measure of the differentiability of a given product technology. We will later see that niche theory needs to be adapted in order to explain all the results obtained in this paper.

\section{3) THE EVOLUTION OF REFINERY PROCESSING}

\section{A brief technical survey}

Petroleum refining consists in the transformation of a raw material, crude petroleum, into a number of useful products. The number and the type of products produced at any given time depend on the uses made of such products, that is on the demand for them, and on the technology available. At the very beginning of the industry the uses of oil were limited to heating and lighting. The oil industry began with the successful drilling of the first commercial well in 1859, and the opening of the first refinery two years later to process the crude into kerosene. The whole development of the petroleum refining industry can be described as the evolution of the methods to separate crude petroleum into its constituents and to transform chemically these constituents.

Crude oils are complex mixtures of hundreds of different species of chemical compounds. Most of these compounds are hydrocarbons, mainly paraffins (alkanes), naphthenes (cycloparaffins), and aromatics, or combinations of these, such as alkyl naphthenes, alkyl aromatics, and polycyclic compounds. In addition, crude oil contains a number of dangerous compounds, such as sulphur or nitrogen and their derivatives, some metals and salt. The main objective of petroleum refining is to separate the components used in different applications and to eliminate the dangerous ones. During the evolution of the industry different types of separation techniques have been used in order to provide the fractions that at each time were in greater demand.

In the early years of the industry there was an understandable tendency among refiners to select amongst the crudes available those with the lowest amounts of difficult materials. Subsequently, due both to the growing demand for this industry products and to improvements in refining technology, less clean crudes were employed.

The number of uses of petroleum derivatives has increased enormously throughout the XXth century. This has been the consequence of the development of a number of industries that use oil derivatives as inputs, such as the automobile, air transport, chemicals etc. Freeman and Soete (1997) consider oil as the main energy system of the fourth long wave in technological development.

Petroleum refining technology evolved from simple distillation processes to a highly sophisticated and differentiated mixture of processes aimed both at separating fractions and at modifying chemically their constituents. This evolution can be represented by the following milestones.

1) At first a refinery consisted of a simple batch, or discontinuous, distillation in which hydrocarbons of successively higher boiling points were vaporized, condensed, and segregated according to the boiling ranges of kerosene, gas oil, and fuel oil (1861, Oil Creek, Pennsylvania). Continuous distillation was soon adopted (18801890). The subsequent evolution of the technology was due to the combined effect of the changing demand for the products of petroleum refining and of changes in the feedstocks used. As the main uses of the products of refining shifted away from heating and lighting towards motoring and chemical applications, the light fractions obtained by distillation became relatively more valuable. On the other hand, the expansion of demand could be 
satisfied by using as inputs heavier and dirtier crudes. Both sets of circumstances induced changes in petroleum refining technology.

2) The discovery (1913) of thermal cracking (a time-temperature dependent decomposition of large molecules into smaller, more desirable molecules) made it possible for the refiner to meet the growing demand for gasoline with a better (higher octane) product.

3) The addition of lead alkyls proved a relatively inexpensive way to upgrade gasoline by increasing their octane degree (1922).

4) Then the catalytic era began. Catalytic polymerization provided a way to utilize the light olefins (principally propylene and butylenes) to produce a high octane gasoline material. Catalytic cracking was considerably superior to thermal cracking in the production of olefins, gasoline, and distillates from gas oil (1937). Hydrocracking is a catalytic cracking process conducted with a high partial pressure of hydrogen relative to hydrotreating processes. It can produce a higher conversion of refractory stocks, that is stocks resistant to cracking, to products of lower molecular weight than those obtained in catalytic cracking processes. Catalytic alkylation was developed as a way to combine isobutane with light olefins to produce very high octane gasoline. Initially, this alkylate was mainly used in aviation. Catalytic reforming followed as a means of upgrading the octane of gasoline range materials principally by converting naphthenes to aromatics. Combined with solvent extraction, this provided a source of benzene, toluene, and of xylenes. Catalytic isomerization permitted conversion of normal paraffins to their more desirable iso forms.

\section{Classification of petroleum refining processes.}

The evolution of different oil refining processes can be represented in two different ways. First, it is possible to classify them logically, according to the similarity of the operations they perform. The block flow diagram representing this classification is shown in Fig. 2. In this classification processes are linked by their technical features, but two processes that are very close technically were not necessarily created at the same or at very close times. That is, logical and chronological proximity do not necessarily coincide. Thus, a second type of classification is based on the times of emergence of the different processes (Fig. 3).

According to the nomenclature of refining processes from Heinrich (1994), a modern very complex refinery may include until 5 principal types of process units:

- $\quad$ Separation: Crude distillation, Absorption, Adsorption, Extraction.

- $\quad$ Reducing average molecular weights (RAMW): Visbreaking, Delayed coking, Fluid/Flexicoking, Fluid catalytic cracking, Heavy oil cracking, Hydrocracking.

- Quality improvement (upgrading): Catalytic reforming, Isomerization, Alkylation, Catalytic polymerization, MTBE and Hydrotreating. The last has the same objective as all the others, but a greater difference of process characteristics.

- $\quad$ Blending treating: removing undesirable component processes. The processes in this type are used to make feed stocks suitable for processing to their best advantage, and it finishes products to meet quality standards. The processes are generally physical in nature, the chemical character of the various hydrocarbons remaining unchanged.

- $\quad$ Finishing: Alsphalt, Coke calcining.

The classification of oil refining processes in Fig. 2 represents the very complex refinery scheme of today. 


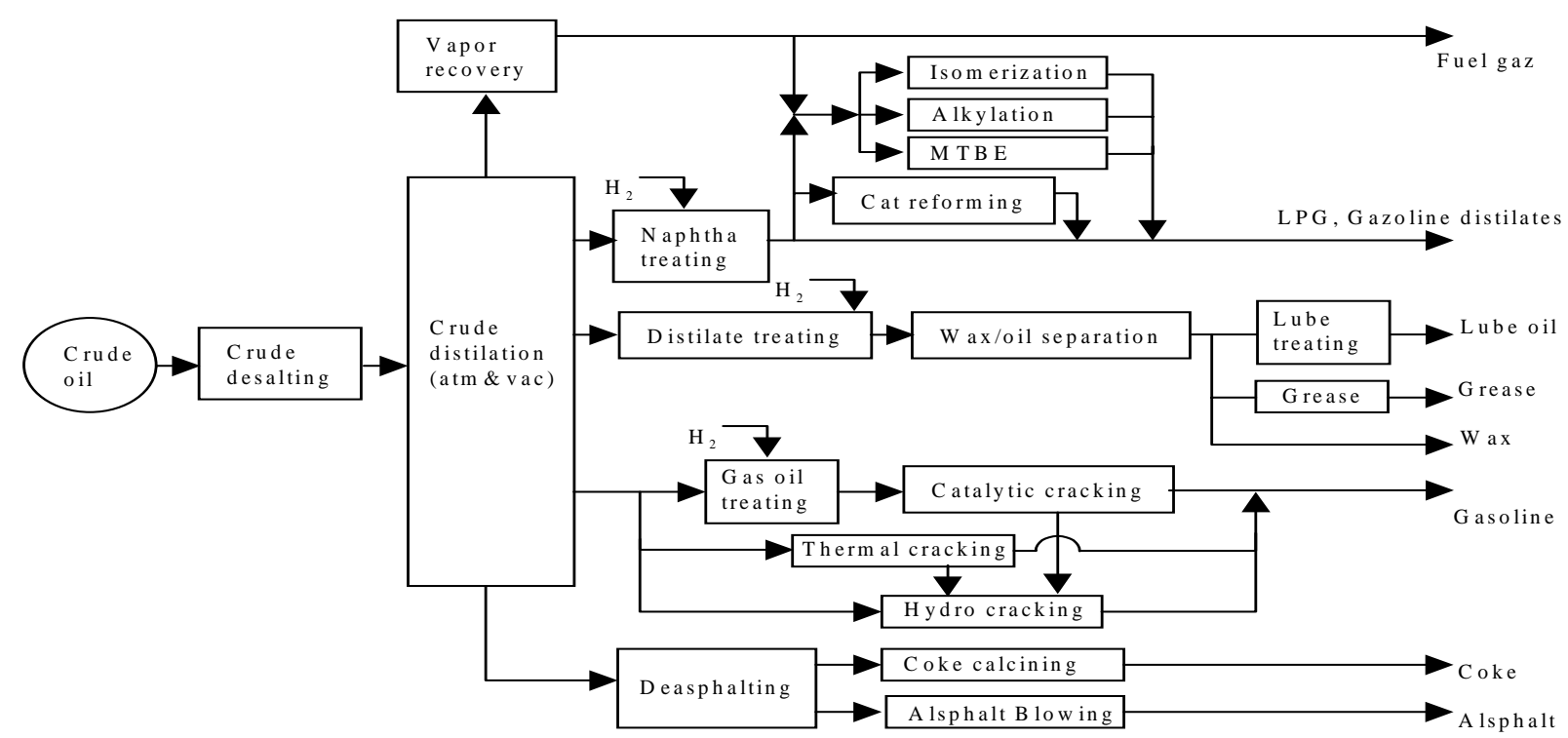

Fig. 2. Diagram of process combination for a 1990's refinery

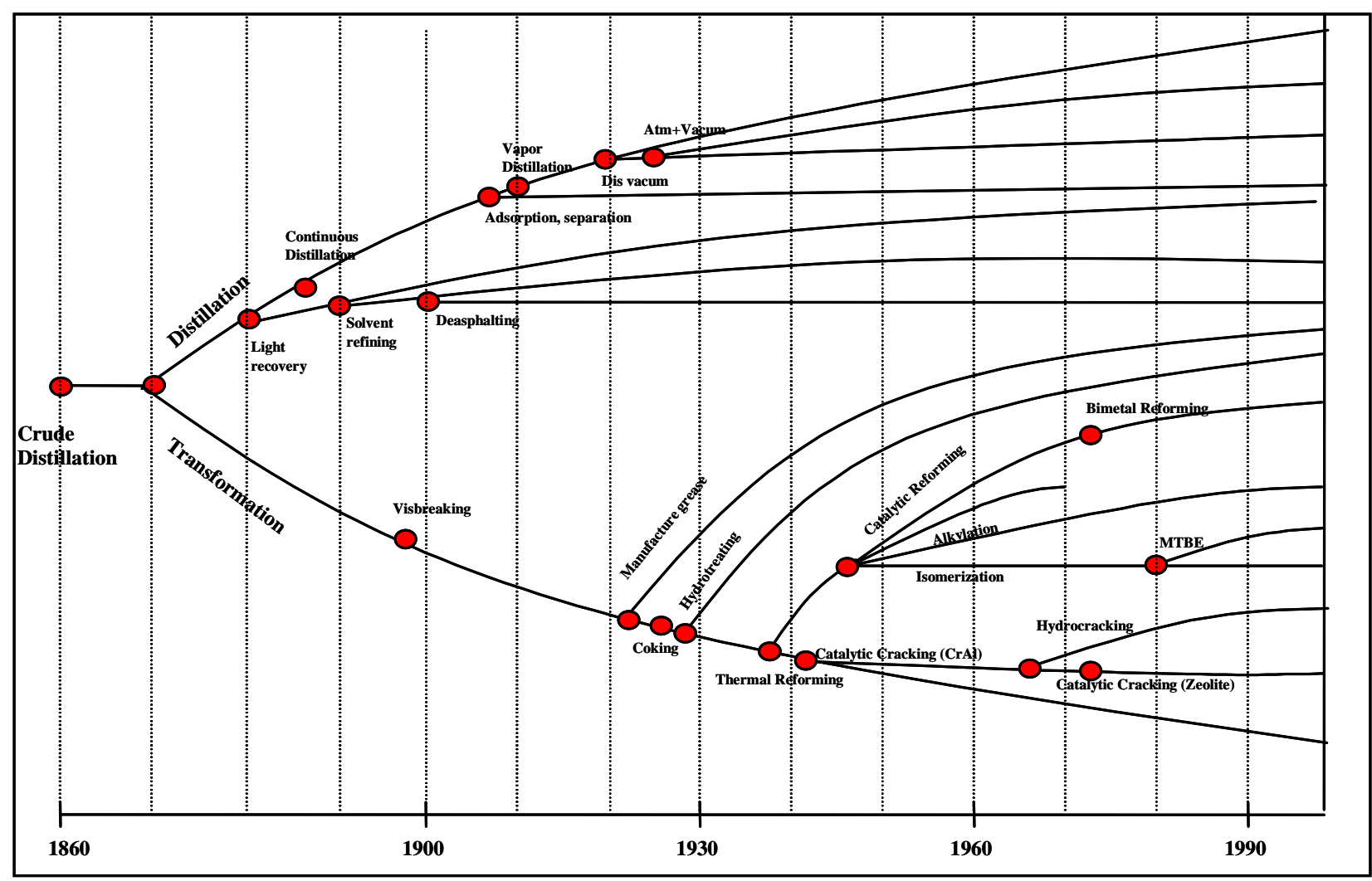

Fig. 3. Evolution of refining technology varieties

The time path followed by oil refining is represented in Fig. 3 in the form of a family tree for the period 1860 2000. The processes are placed on two different main branches corresponding to distillation, involving only a physical separation of the components of crude petroleum, and to chemical transformation respectively. Within each of these branches diversification into several smaller sub-branches takes place.

The family tree is based partly on the same data that we used for the calculations of variety, covering the period 1932-1998, and partly on data from other sources. The information required to construct the family tree is essentially the date of origin of each process and the knowledge we have about the nature of the process. Fig 3 leads us to expect that the variety of petroleum refining increased for the period studied. However, the figure is based on a bias that leads us to exaggerate the degree of radicalness of the innovations involved. In constructing 
the diagram we have a tendency to superimpose our judgement on the data, as, for example, when we place two processes on two different branches of the diagram. For example, we place catalytic cracking and continuous distillation on two different branches because we think that the former involves some chemical transformation while the latter is based on an exclusively physical separation. Furthermore, the presence of a catalyst requires new technical characteristics to be introduced to describe the process. We can see here that the distinction between radical and incremental innovation involves an essential ambiguity when applied to very complex production systems. Even if the innovation introduced in a single part of the system is radical (it requires a new variable) its 'weight' as a percentage of the changes of the whole production process may be very small when the rest of the process remains unchanged. Furthermore, the addition of a particular set of technical characteristics to an existing process may have a gradual influence on the performance of the process, however radical the new technical characteristics are. This ambiguity is at the heart of the differences we find between the family tree of Fig 3 and the results of our subsequent calculations.

In what follows we are going to calculate the variety of petroleum refining based on a number of process variables, such as the range of temperatures and pressures used, process yields etc.. A priori we cannot expect the results of these calculations to coincide with the those of Fig 3, for at least two reasons. First, the deaths of old processes are not included in Fig. 3. Second, the same continuous variables are used to represent all the processes, thus creating the opposite bias with respect to the one present in Fig. 3. That is, this second method will tend to understate variety growth. Before describing these calculations a short survey must be made of the main factors explaining the emergence of new refining process

\section{Inducements to the creation of new refining processes}

Constraints and flexibility of the refining process

Petroleum refineries are designed and operated to run within a narrow range of crude oil feedstock, and/or to produce a relatively fixed mix of petroleum products, which should match a local market. However, since the 1970s refiners had to increase their flexibility in order to adapt to a more volatile environment. Several possible paths may be used by refiners to increase their flexibility within existing refineries. Examples of these paths are change in the severity of operating rules of some process units by varying the range of inputs used, thus achieving a slight change in output. However, this option is available only within a narrow range. Other possible paths are to buy some chemical intermediate products rather than making them, or to use more efficient catalysts. Alternatively refiners can invest in new processes. This alternative offers the greatest flexibility, but is limited by the constraint of strict complementarily of the new units with the rest of the existing plant and involves a higher risk than the previous ones. Thus, we can expect refiners to decide in favour of modifying existing processes or of adopting new ones depending on a) new technological opportunities, and b) new market factors.

New scientific and technological opportunities can either reduce refining costs for a constant petroleum products mix, or enable refineries to use a modified mix of petroleum products to supply the changing markets of the refinery. Incentives to reduce costs are partly linked to the conditions of competition existing within a given market. The previous considerations imply that the adoption of a new refining process will take place only after other options to increase the flexibility of existing refining processes have been exhausted. Incentives may also be linked to a drastic change in the crude market, as it happened for example with the two oil price shocks in 1973 and 1979/1980. As a consequence of those shocks the relative price of 'sweet' and 'light' crudes, that contained either a low fraction of sulphur and a high proportion of more valuable petroleum fractions, increased with respect to the price of the sour and low API gravity ones. Adapting to this change refiners, especially in the United States, tended to buy increasingly the cheapest crudes, ie. the dirtiest and lowest API gravity ones, on the world market. This shift required a higher conversion ratio, which could be obtained by cracking the residue of previous units, thus transforming it into usable products. Thus, whether modifications of existing plants or the adoption of completely new processes prevail is likely to depend on the extent of the extent of change in the external environment.

US refiners could adopt this "buyer" strategy because most US refineries are "very complex" ones, that is they include the highest conversion intensity and the most sophisticated hydrotreatment process units. Such refineries are able to process sour and heavy crude oil, despite the more severe specifications for petroleum products quality. The same interaction could be found within catalyst development: "In general, new products introduced by catalyst manufacturers are designed specifically to meet environmental and safety concerns or to improve performance and cost. Often, new catalysts do both" (OGJ, Oct 9, 2000, p.66). These developments illustrate the intimate relationship between demand-pull and supply-push factors. 


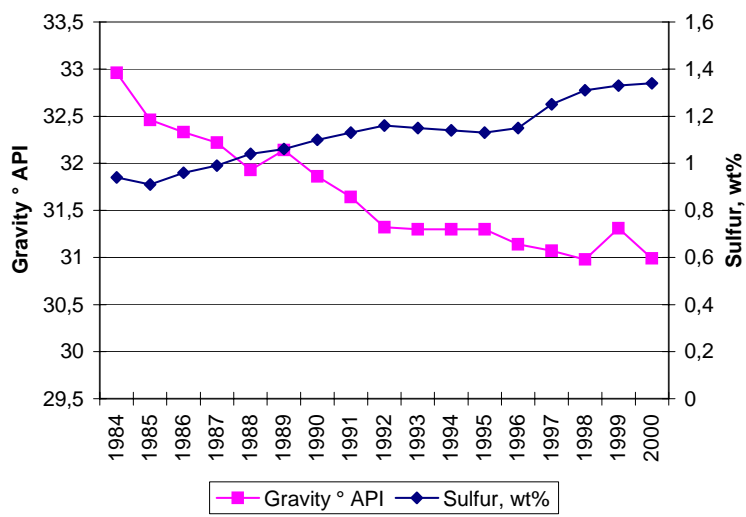

Fig4: Average API gravity and average sulphur content of crude oil inputs in US refineries (1970/2000).

Source: authors, from US DOE, Petroleum Supply Annuals

\subsubsection{Scientific and technological opportunities which may explain new refining processes}

Given the continuous progress in chemical engineering, the increased performance of materials and catalysts, three broad trajectories ${ }^{2}$ can be identified:

1. Emergence of new processes with new specific functionalities. Examples of these are either entirely new processes, such as the fractionating bubble tower in 1927, and the short contact time technology for fluid catalytic cracker in 1997, or combinations/integrations of existing ones, such as hydrocracking, obtained at the beginning of the 1960s by the integration of hydrotreating and cracking,

2. $\quad$ More efficient processes by:

- shifting from thermal ones to the new and more energy efficient catalytic ones. For example, the first fluid catalytic cracker (FCC) was operated in 1937 to replace a thermal cracker.

- substituting batch or discontinuous processes with continuous ones, including the regeneration of used catalysts - shifting to new catalysts, such as zeolite or bimetallic to increase catalyst efficiency, thus improving yield and selectivity ${ }^{3}$. A zeolite catalyst has first been used in a hydrocracking process.

3. Adoption of more flexible processes by changing feedstocks, as it happened in 1943 by replacing naphtalene with xylene as feedstock in the hydroforming process.

If we focus on the emergence of broad "families" of new processes, we can identify two main historical periods, before and after the end of the second world war respectively. The main building blocks of refinery technology had been designed and implemented before 1944. Drawing from a Principal Component Analysis between 1949 and 1998, Bel and Bourgeois (2003) identify three stages in the technological path of the main families implemented : i) from 1954 to 1964 a strong presence of thermal conversion and upgrading processes, ii) after a transition from 1966 to 1970, a wave of new absorption and hydrotreating processes between 1982 and 1988 , iii) thirdly in the 1988 to 1998 sub-period, a phase of diversification in various technical families.

As previously mentioned, these technological developments are closely linked to market factors.

\section{The influence of demand on new refining processes}

From the end of 1940s until the end of the 1960s, and in spite of local /regional conflicts ( Korea, Suez), the world petroleum products market has been governed by an astonishing stability regarding its global growth ( +5,3\% /year) (B.Château, B. Lapillonne, 1999). Despite regional differences, the industry was characterized by a general trend towards a larger share of "light” petroleum products (gasoline, diesel, petrochemical products) and a declining share of heavy fuels. A considerable number of changes in product specifications occurred simultaneously, such as the trend towards an increasing octane number for gasoline.

\footnotetext{
${ }^{2}$ All the following examples are taken from "Refining Milestones" published in Oil \&Gas Journal, Dec 13 1999, p.116.

3 An example of such improved performance at a lower cost may be quoted in 1998 with Azko Nobel "new hydroprocessing catalysts designed with high-activity to reduce the amount of new equipement needed to meet sulfur limits" Oil and Gas Journal , Refining Catalyst demand, Oct.9, 2000, p.66
} 
As previously pointed out, we could expect petroleum refiners and their process suppliers to opt whenever possible for a continuous adaptation of their refinery configuration, eventually including new commercial process units. This adaptation was a relatively easy task because on one hand the rate of growth of demand was fairly stable, allowing eventual errors for investment in new refining capacity, and on the other hand the ongoing technical change trajectory was based on a continuous "stream of improvements" (Enos J.L., 2002) . With regard to this trend, the editors of Petroleum Refiner made the following statement in September 1949 : “ Also not apparent, but vitally important, is the constant improvement in the operating processes. Much of this yearly gain is in the field of mechanical design. While feed stock products, operating conditions, and equipment arrangements are almost endlessly variable, it may be surprising to some to note how uniform are the requirement of processes in regard to the equipment components from which they are assembled. The fact is that equipment design for the processes industries has reached a high level of development and standardization, ” ( $\mathrm{p}$. 113). To summarize, demand and supply conditions in the refining industry during these thirty years were very stable. Decision-makers were facing a predictable selection environment in which innovations had been mostly incremental, although the long term impact of these cumulative incremental innovations was quite impressive.

The situation changed dramatically during the 1970s, due mainly to the oil price shock. While this can be considered the main underlying change, it led to increased competition between refiners and to the implementation of major environmental regulations. ( EIA, 1990). Thus, on balance we can consider the overall evolution of petroleum refining as constituted by an early period (1860 -mid 1970s) of steady and predictable growth, during which process innovations tended to be incremental, and by a later, post 1970s period, during which economic turbulence increased considerably.

Four demand related factors influenced the evolution of petroleum refining. First, there was the long term structural shift from lighting and heating uses towards motor fuels and petrochemical ones. This trend developed earlier in the US due to its far higher income per head and to the enormous relative size of the US market. Types of consumption dependent on a high income per head, such as motoring, developed earlier in the US than anywhere else. The relative share of kerosene, distillate fuel and residual fuel oil fell from $53 \%$ to $42 \%$ between 1919 and 1939 while simultaneously the share of motor fuels rose from $24 \%$ to $45 \%$ for the same years. In the last forty years (1965/2005) demand for light distillates increased at a combined rate of $+0,9 \%$ annually, while demand for fuel oils declined at a rate of 0,8\% annually (Source : Absi Alabi, et al, 1997). Because no available crude feedstocks could match this demand shift, the only way to adapt to it was to increase the conversion intensity through new refining processes. In 1912 the first practical means of cracking oil to get gasoline through the Burton thermal cracker was invented by William M. Burton. This first cracking process was later followed by many other thermal and then catalytic ones.

The second factor stems from the emergence of new uses of petroleum or petrochemical products which were previously considered as useless by-products, such as isopropyl alcohol obtained for the first time in 1920 from the processing of gaseous refinery by-products, or the discovery of butyl, which then became used in the production of artificial rubber.

The third and fourth factors are both due to the increased quality of petroleum products, caused by improvements in petroleum using technologies or by more severe environmental constraints. The best example of the third factor is the increasing compression ratio of motor cars, which demanded increasing octane numbers of gasoline (Fig. 5).

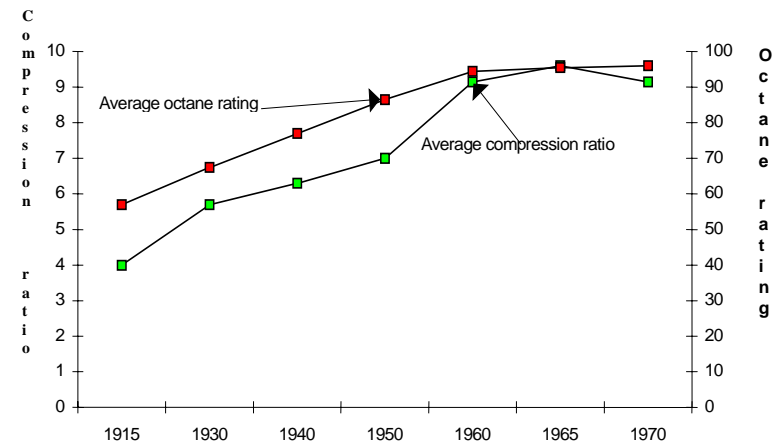

Fig.5 : Average compression ratio for new automobiles and average gasoline octane rating in USA -1915 /1970. Source : authors, from API, 1959 
In order to increase octane numbers different methods have been used: addition of tetraethyl lead to the gasoline pool; use of new catalysts or new processes, such as reforming, FCC, alkylation and isomerization. Many other examples could be quoted in the lubes area, where there is an increasing trend towards more severe specifications (resistance to high temperatures, low recycling ...) which can only be matched by the synthesis of lubes from petrochemical feedstock.

The fourth factor, the increased environmental quality of petroleum products, is of much more recent origin but it has been gaining a growing importance. This factor emerged in the early 1970s in the USA, later diffusing to the rest of the world, particularly to the European Union and to Japan. The increasing severity of the new environmental specifications for gasoline and for diesel motor fuels in developed countries required a decreasing sulphur content, a decreasing aromatics content, and a lower Reid Vapour Pressure (RVP) (Table 3). These new specifications are the technical translation of the so called "greening" of technological progress (Kemp R., Soete L., 1992), i.e. of the incremental innovations which reduce the environmental impact of some key features without changing the technology base of the industrial conversion process.

Table 3: Historical and future trends in gasoline and diesel specifications in developed countries

\begin{tabular}{|c|c|c|c|}
\hline \multicolumn{2}{|r|}{ Gasoline } & \multicolumn{2}{|r|}{ Diesel } \\
\hline Period & Specification & Period & Specification \\
\hline $\begin{array}{l}\text { Prior to } \\
1994\end{array}$ & $\begin{array}{l}\text {-Lead phase out } \\
\text {-Lower Rvp }\end{array}$ & $\begin{array}{l}\text { Prior } \\
\text { to } 1993\end{array}$ & $\begin{array}{c}\text {-Sulphur : } 1,0 \%-0,2 \% \\
\text { (Sweden: } 0,001-0,05 \% \text { à } \\
\text { from 1991) } \\
\text { - Cetane : No limits } \\
\text { (Sweden: } 47-50 \text { from } \\
1991 \text { ) } \\
\text {-Aromatics : No limits } \\
\text { (Sweden : } 5-25 \% \text { from } \\
\text { 1991) }\end{array}$ \\
\hline $\begin{array}{l}1995- \\
2000\end{array}$ & $\begin{array}{c}\text { Reformulated gasoline } \\
\text { (Phase 1) } \\
\text {-Zero lead } \\
\text {-Benzene : } 1 \% \text { max.; } \\
\text {-lower aromatics : } 25 \\
\text { vol. \% max. } \\
\text {-Oxygen : } 2 \% \text { wt min } \\
\text {-Rvp : 7,2/8,1 psi max. }\end{array}$ & $\begin{array}{l}1993- \\
2000\end{array}$ & $\begin{array}{l}\text {-Sulphur : 0,2-0,05\% } \\
\text { - Cetane : 40-46 min } \\
\text {-Aromatics : 35\% max } \\
\text { (California : 10\%) }\end{array}$ \\
\hline $\begin{array}{c}\text { Beyond } \\
2000\end{array}$ & $\begin{array}{c}\text { RFG : (Phase II) } \\
\text {-Lower sulphur content } \\
\text { : } 30 \text { ppm } \\
\text {-Benzene : } 0,8 \% \text { max; - } \\
\text { Aromatics : 22\% max } \\
\text { - Rvp :7,0 psi max. } \\
\text { - Olefins : } 4 \% \\
\text {-Oxygen : > } \%\end{array}$ & $\begin{array}{c}\text { Beyond } \\
2000\end{array}$ & $\begin{array}{c}\text {-Sulphur : Further } \\
\text { reductions to Swedish } \\
\text { levels } \\
\text {-Cetane : Further increase } \\
\text {-Aromatics: Further } \\
\text { reduction } \\
\text {-Volatility : Increase over } \\
\text { present level }\end{array}$ \\
\hline
\end{tabular}

Source: Absi-Halabi M., Stanislaus A., Qabazard H.,1997

\section{4) METHODS AND RESULTS}

\section{1) MEASUREMENTS OF VARIETY.}

\subsection{Measurements of variety}

The measurement of variety during product evolution is a major problem in empirical studies of innovation. FrenkenSaviotti and Trommetter (1999) adopted two measures of variety: the entropy measure, indicating the statistical variety on the basis of frequency distributions of discrete variables, and Weitzman's measure, which is based on a distance measure between entities, applicable to both discrete and continuous variables. In this paper, due to the limitation of our database, which includes only continuous variables of refinery processes, we apply Weitzman's measure.

\subsubsection{Weitzman measure of diversity}


Weitzman's (1992) measure was initially developed to measure biodiversity, as an alternative to other functions (e.g. entropy) which were already available. Subsequently this measure has been used to map changes in variety for several sectors, such as microcomputers, aircraft, helicopter, motor cycle etc. by Frenken, Saviotti and Trommetter (1999, 2000). Irrespective of its field of application, Weitzman's measure classifies entities in groups based on their similarity. Similarity is to be considered here as the reverse of distance. The measure obtained in this way gives a value that increases the greater the number of distinguishable entities and the larger their distances, or the greater their dissimilarity.

Weitzman's measure of diversity is based on a maximum likelihood grouping procedure, using some distance measure "'d" (difference or degree of dissimilarity). In the following, we use a notation in which $i$ and $j$ stand for different members of a population. In this paper the terms diversity and variety are to be considered as synonyms.

The distance measure needs to satisfy the following conditions:

$$
\begin{aligned}
& d(i, j) \geq 0 \\
& d(i, i)=0 \\
& d(i, j)=d(i, j)
\end{aligned}
$$

We suppose that there exists a non empty set $S$, whose value of diversity $V(S)$ is the solution of the recursion:

$$
\mathrm{V}(\mathrm{S})=\max _{y \in S}(\mathrm{~V}(\mathrm{~S} \backslash \mathrm{y})+\mathrm{d}(\mathrm{S} \backslash \mathrm{y}, \mathrm{y}))
$$

where S\y stands for a set S without product $\mathrm{y}$ and $\mathrm{d}(\mathrm{S} \backslash \mathrm{y}, \mathrm{y})$ for the distance between this set and product $\mathrm{y}$. The solution of the recursion is unique once the initial conditions, $\mathrm{V}(\mathrm{x}) \equiv \mathrm{d}_{0}, \forall \mathrm{x}$, are specified for any $\mathrm{d}_{0}$ (we simply take $\mathrm{d}_{0}=0$ ). This formula holds that the diversity of a population is the maximum, over all members in the population, of the distance of a member from its closest neighbour, plus the diversity of the population without that member. Since the computing time needed to calculate Weitzman's measure grows exponentially with the number of observations, we are forced to work with a relatively small number of observations per period.

Weitzman argued that his distance is a useful measure because it has the properties that are usually associated with diversity, thus proving to be a useful measure from a purely pragmatic point of view. There are five of these properties (Frenken, Saviotti, Trommetter, 1999):

I. Monotonicity in elements: if we add a new element y to a set S that does not already contain y, then the diversity value increases at least by $\mathrm{d}(\mathrm{S}, \mathrm{y})$.

II. Twin property: if we add an element $\mathrm{y}$ that is identical to some element $\mathrm{x}$ belonging to $\mathrm{S}$, that does not modify the diversity.

III. Link property: there exist at least one element y in $\mathrm{S}$ that verifies : $\mathrm{V}(\mathrm{S})=\mathrm{V}(\mathrm{S} \backslash \mathrm{y})+\mathrm{d}(\mathrm{S}, \mathrm{y})$.

IV. Continuity in distances: let $|S|=\left|S^{\prime}\right|$ such that $S$ can be mapped one-to-one onto $S^{\prime}$, then it can be shown that for $\forall \varepsilon>0$, it holds that $\left|\mathrm{V}(\mathrm{S})-\mathrm{V}\left(\mathrm{S}^{\prime}\right)\right|<\varepsilon$.

V. $\quad$ Monotonicity in distances: if all distances between elements of S increase, V(S) increases.

A crucial aspect of Weitzman's measure is the choice of distance measure. In general, different distance measures will generate different diversity values for the same set. In general we have to choose what seems to be the most appropriate distance measure for the task at hand and, in particular, to keep using the same measure in any comparison of the diversity of different systems.

\subsubsection{Distance measure}

Given an $n^{*}$ m data matrix $\mathrm{Z}$, where rows correspond to product models and columns to product characteristics, we compute a distance matrix D. For row distances, the $\mathrm{X}(\mathrm{i}, \mathrm{j})$ element of the distance matrix is the distance between row $\mathrm{i}$ and row $\mathrm{j}$, which results in a nxn $\mathrm{X}$ matrix. In this study, $\mathrm{n}$ represents the number of observations and $m$ represents the number of variables.

In order to simplify the calculations, we use the normalized matrix $\mathrm{X}$ defined as:

$$
X(i, j)=\frac{Z(i, j)}{\bar{Z}(j)} \quad \mathrm{i}=1: \mathrm{n}
$$

where $\bar{Z}(j)$ is the mean value of the variable j determined by: 


$$
\bar{Z}(j)=\sum_{i=1}^{n} \frac{Z(i, j)}{n}
$$

By letting $X_{i}$ and $X_{j}$ represent the $i^{\text {th }}$ and $j^{\text {th }}$ row vectors of matrix $X$.

The Euclidean row distance of the matrix $\mathrm{D}$ between observations $\mathrm{i}$ and $\mathrm{j}$ is defined as

$$
d(i, j)=\sqrt{\left(X_{i}-X_{j}\right)\left(X_{i}-X_{j}\right)^{t}}
$$

We use the Euclidean distance, which is simply the square root of the squared differences between corresponding elements of the rows. This is probably the most commonly used distance metric.

\subsubsection{Classification methods}

Both the computing time needed to calculate Weitzman's measure and the accuracy of the corresponding calculations increase with the number of observations. Unfortunately the computing time grows exponentially with the number of observations. Even with today's computers computing time rapidly becomes excessive. For this reason, we reduce the whole population of observations to a smaller but representative sample. Several approximations are possible to reduce the number of observations to reasonable values. For example, Frenken Saviotti and Trommetter (1999) adopted a method of random choice of observations. First, they ranked the observations based on their average Euclidean distance. Then they divided the rank distribution in 17 groups and picked randomly one observation from each group. This procedure was repeated three times, thus yielding three samples for each year.

In this paper we developed a more systematic classification method based on the similarity of characteristics. The purpose of this method is to make the best possible selection of all the observations available, thus constructing a sample that is reasonably representative of the whole population, in order to reduce computing times to reasonable values. The classification method works by first computing the proximity between objects in the data set, and then by grouping together in clusters the objects with the greatest proximity. The proximity is the inverse of the distance. To test the robustness of our classification method we use two distance measures. These classification algorithms are based on various measurements of proximity between two groups of objects. If $N_{\mathrm{r}}$ is the number of observations in cluster $r, N_{\mathrm{s}}$ is the number of observations in cluster $s$, and $x_{\mathrm{ri}}$ is the $i^{\text {th }}$ observation in cluster $r$ the definitions of these various measurements are as follows:

\section{Smallest distance method}

To compute this type of distance we calculated the smallest distance between objects in the two groups:

$$
d(r, s)=\operatorname{Min}\left\{\operatorname{dist}\left(x_{r i}, x_{s j}\right)\right\}, i=1: N_{r}, j=1: N_{s}
$$

\section{Average distance method}

To compute this type of distance we calculated the average distance between all pairs of objects in cluster $r$ and cluster $s$.

$$
d(r, s)=\frac{1}{N_{r} N_{s}} \sum_{i=1}^{N_{r}} \sum_{j=1}^{N_{s}} \operatorname{dist}\left(x_{r i}, x_{s j}\right)
$$

The classification function takes the distance information and links pairs of objects that are close together into binary clusters (clusters made up of two objects). The classification function then links these newly formed clusters to other objects to create bigger clusters until all the objects in the original data set are linked together in a hierarchical tree. In other words, this procedure gives us a method to reduce systematically the number of observations required to calculate Weitzman's variety measure.

\subsubsection{Methodology}

As we already pointed out, both the computation times and the accuracy of the calculations of Weitzman's variety increase with the number of observations. We already described the use of a classification method in order to reduce the number of observations, and thus of computation times, to reasonable values. Computation 
times remain nevertheless quite high. Since the number of observations is not identical for each year, we have to choose the same number of observations for every year in order to calculate a Weitzman's measure. This is crucial because the Weitzman's measure is sensitive to the number of observations. The accuracy of calculation of Weitzman's measure depends strongly on the selection of observations. The algorithm of this method is as follows:

- Calculate distances between the elements of the X matrix, by using (3)

- Choose the number of observations $\mathrm{N}_{\text {obs }}$ to calculate the Weitzman's measure of diversity;

- $\mathrm{N}_{\text {obs }}$ groups of observations are formed by using the classification methods defined by (4) or (5); in each group there are different numbers of observations

- In each group, choose randomly one observation; therefore there are $\mathrm{N}_{\mathrm{obs}}$ observations to calculate the Weitzman's measure of diversity

- Weitzman's measure of diversity for these observations is calculated by using (2)

- Print results and graphics

If the procedure used to calculate Weitzman's distances may seem complicated and somewhat abstract, its intuitive meaning is clear. We can imagine to place all distinguishable product models on a family tree, with each product occupying a different branch. The variety measured by Weitzman's technique can be expected to increases with the number of branches and with their distance. Thus, Weitzman's measure indicates the degree of differentiation within product populations at any level of aggregation. If we had data about all the types of output of an economic system Weitzman's distances would indicate the degree of differentiation of this economic system. A demonstration of the use of this method is provided in the appendix 1.

\section{2) APPlications AND RESUlts}

\section{Results for refinery processing}

Our definition of the concept of variety allows us to translate it into measurements. The definition Variety is "the number of distinguishable types of actors, activities and outputs present in an economic system at a given time", can be applied to measure variety, $\mathrm{V}$, provided we have available the required data. In the present case we have very accurate information about a sample of processes, or activities, very limited information about the nature of the outputs produced and no information about the firms (actors). Thus, our measure of variety will be an approximation based on the number of processes. As already pointed out, the variety we are going to calculate here is process variety, which means that we cannot expect for it the same trends in the course of time as for output variety.

We applied Weitzman's variety measure to a database containing seven continuous process characteristics ( see appendix 1) for 516 different process units introduced during a period ranging from 1932 to 1998. Both the variables describing each process and the distribution of new processes are given in Tables A1 and A2 in Appendix 1 and 2. Our variety measure thus focuses on the technological evolution of an industry as expressed in changes of process characteristics in new processes over time and not on the industrial evolution in terms of market shares.

The number of processes introduced per year differs greatly for our data set. Thus, the distribution of new process offering is not uniform in time. However, to analyse the change of variety of a process population over time, it is preferable to deal with periods containing the same number of observations, since the Weitzman measure is sensitive to the number of observation.

For each period, we calculated the Weitzman measure for a number of groups of observations ranging from 9 to 23 and for each number we made 20 simulations. Fig. 6 and Fig. 7 display the results of our calculations using the smallest and the average distance for all periods respectively. Furthermore, in the two figures we can see how the calculated values converge towards a common trend as the number of groups increases. This gives us a guarantee that our measure is related to the technological nature of the phenomenon rather than being purely the result of the techniques used in the calculations. In spite of this convergence the results obtained for different numbers of groups are not identical. We have previously pointed out that we can expect the results obtained with a larger number of groups to be more accurate. Therefore, in the interpretation of these results we tended to give more weight to the measures obtained with a larger number of groups. 


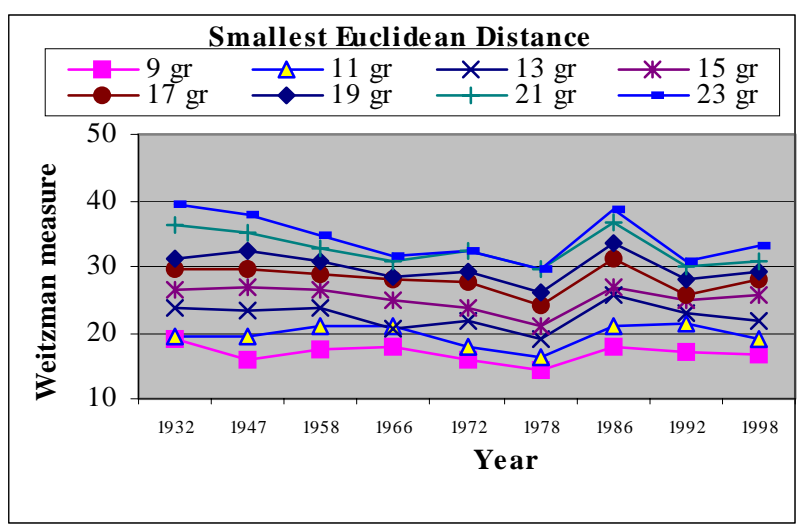

Fig. 6: Variation of the Weitzman measure using the smallest Euclidean distance

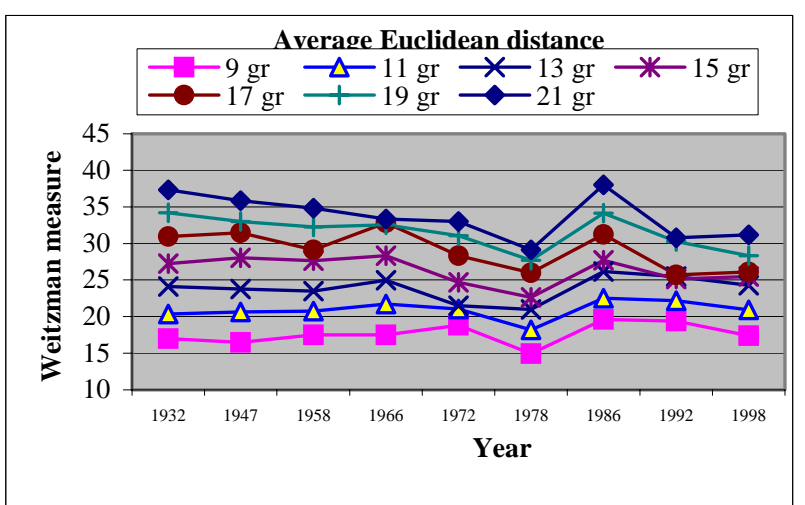

Fig.7: Variation of the Weitzman measure using the average Euclidean distance

\section{Analysis}

Our calculations of the Weitzman measure for continuous process characteristics indicate for refinery processing a long-run trend towards a decreasing variety over time from 1932 to 1978, a rapid growth in variety between 1978 and 1986, and a trend which is more difficult to interpret after 1986. Between 1986 and 1992 variety seems to fall rapidly, but after 1992 it grows slightly. Clearly the period before 1976 was characterised by much smoother changes than the subsequent one. For the time being it is also clear that in 1976 there was an important shock, although it is not yet clear whether in the following period petroleum refining is likely to go back to the previous trend or to begin a new and different one. Within the uncertainties involved in these measurements we conclude that after 1992 a trend towards a slowly growing variety was operating. Thus we divide the total period studied into two sub-periods, covering the years 1932-1978 and 1978-1998 respectively.

The declining trend from 1932 to 1978 can be interpreted as due to an increase in the average performance of petroleum refining coupled to a fall in the dispersion of the performance of the same technology. Given that our data base does not contain information about market shares or about the composition of the stock of capital equipment of petroleum refiners, we can conclude that every new refining technology introduced increased average performance but reduced the dispersion of the various process characteristics. This is a trend that can be expected within a given technology that is improved incrementally and thus comes closer to its frontier. The overall rising trend in the period after 1978 can be explained by the emergence of new process units aiming at quality improvement, such as the synthesis of Ethers (MTBE, ETBE, TAME...) and the re-emergence of process units, such as Finishing or Coke calcining, working at lower pressures. We use the term re-emergence here because the original process has been in existence since 1932. There were a lot of new process units designed for quality improvement, such as Catalytic reforming, Isomerization, Alkylation, Catalytic polymerization, or those intended to reduce average molecular weights, such as Fluid catalytic cracking since 1947. New process unit intended to reduce average molecular weights (Hydrocracking), which played both the roles of cracking and of treating, were created since 1966. However, the emergence of all these process units did not increase the Weitzman measure in our Figs. 6 and 7 until 1978. Such a trend would be explained if new units were only a modified version of those already in operation. This would be possible if all the new units belonged to the same dominant design (Utterback, Abernathy, 1975) as the older ones. However, the concept of dominant design has 
been formulated with respect to industries where product technology plays a very important role, at least at some stages of their life cycle. Oil refining seems to be an industry where product design plays a very limited role and to which we cannot necessarily expect that the concept of dominant design to apply. In fact, the oil refining industry evolved by adding new complementary units, which did not fundamentally affect earlier investment. These successive vintages are still present and still make substantial contributions to meeting requirements.

The increase in variety that took place after 1978 is quite likely due to the effect of the oil price shock that occurred at the beginning of the same decade. For the moment we limit ourselves to observe that the predominant trend has been towards decreasing variety until 1978 followed by an important shock (rise and fall) between 1978 and 1992, and by a gentle increase after 1992 (Figs. 6,7).

\section{5) INTERPRETATION AND CONCLUSIONS.}

\section{1) INTERPRETATION.}

The previous results can be summarized as follows:

- $\quad$ The process variety of oil refining generally declined in the period 1932-1978, it underwent an important shock between 1978 and 1992, and subsequently seems to have been increasing slowly. Thus the period 1932-1998 can be divided into the two sub-periods 1932-1978 and 1978-1998;

The number of distinguishable new process technologies in oil refining kept increasing all throughout the period studied.

We have already seen that the period up to the mid 1970s had been one of steady and predictable demand growth for the petroleum refining industry, and that in these circumstances we could expect both producers and equipment suppliers to opt for incremental innovations in order to remain competitive. In this situation we could expect competition to eliminate gradually the less "fit" processes and producers. Such an evolution can be predicted on the basis of evolutionary growth models (Nelson, Winter, 1982) and of the dominant design approach (Utterback, Abernathy, 1975; Utterback, Suarez, 1993). It is rather doubtful that the concept of dominant design is applicable to oil refining. The products of the industry are as design-free as possible, being constituted by a mixture of chemical compounds. However, we cannot exclude that constant plant designs are used for long periods, with only incremental innovations differentiating the newer vintages from the pre-existing ones. Whether or not there is a dominant design in petroleum refining, we can still expect productivity variance in the population of firms to become gradually narrower, a trend that Nelson and Winter (1982) consider an expression of Fisher's fundamental principle of natural selection applied to economics (p. 243). Thus, the fall in process variety during the period 1932-1978 would find a very easy explanation if the technology had only become more efficient by eliminating the less "fit" variants that had come into existence in the early phases of the life cycle. Of course, we can expect this trend to continue only as long as the selection environment remains stable. If important changes were to take place in the selection environment, only few producers would be able to adapt, for example by introducing more radical innovations. In these conditions we expect that the range of technological performance offered by equipment producers would increase.

Our analysis concentrated almost exclusively on process technologies. In particular, the data we used were the physical conditions in which the processes took place, the yields, etc. . Given that we are dealing with a process technology, in our case we will call these variables process characteristics. Our results can then be interpreted as saying that the dispersion of process characteristics in oil refining generally declined in the period 1932-1978 to increase again after 1978 .

During the 1932-1978 period process variety fell while the number of distinguishable process technologies increased, corresponding to a higher output variety. This apparent contradiction between the family tree and the results of our calculations depends on the opposite biases of the methods used to construct Fig 3, which overstates variety growth, and that used for the subsequent calculations, which tends to understate variety growth. These different biases of the two methods follow from the tendency of the first to exaggerate the radicalness of the innovations and that of the second to exaggerate the incremental character of the same innovations. When we construct family tree we subjectively decide that two processes are sufficiently different to be placed on two different branches. For example, should a process to which a catalyst has been added while leaving unchanged all or most of the rest be on separate branch? By means of this approach in most circumstances we are likely to overstate the variety of the system. On the other hand, when we calculate the variety of petroleum refining by means of a data base in which all possible processes are represented by the same set of continuous variables we are likely to find smoother and more gradual variations. We could then conclude 
that the real path followed by the variety of petroleum refining is in between the ones detected by Fig 3 and by the subsequent calculations. We would, however, be inclined to give a greater weight to the calculations for their more objective character, although we recognise that the data we used are in the mean time very extensive but not complete. Thus, our data do not adequately represent the changes in quality and the growing proportion of light fractions in the output of petroleum refining. If such information were added to our data base we expect that only small changes in the results of our calculations would take place. The main pattern observed seems to us to make sense because most of the processes introduced until 1978 were combinations or recombinations of previous technologies.

Whatever the reasons for the fall in process variety during the 1932-1978 period, it is clear that an important change took place around 1978. The date at which this change in the selection environment occurred is quite likely related to the onset of the first oil crisis, consisting of a very rapid rise in oil prices after a long period of regularly declining prices. Such a change was so powerful that we describe it as a shock. The effect of such a shock was to induce innovations that represented a break with respect to the previous evolution of the technology. After rising for almost fifty years process variety grew rapidly between 1978 and 1986. The subsequent fall between 1986 and 1992 led to a more moderate growth between 1992 and 1998. In this moment we cannot foresee whether the 1978 shock was temporary, and thus whether petroleum refining is going to return to the previous declining trend, or whether a new trend will be established after the shock. The only possible interpretation of the slight rise during 1992-1998 is the increasing environmental constraints faced by refiners and consequently by plant producers.

Whatever the future evolution of petroleum refining we have to explain why variety started rising as a consequence of the oil price shock. Clearly, in this case it was not technology that initiated the changes, but changes in the selection environment having to do mostly with the relative power of petroleum producers. Neither the real scarcity of petroleum nor the demand for it changed in such a drastic way. Whatever the interpretation given to the post 1973 events in the oil market, technology was not the cause, but an effect of those events. Technology responded to these events and improved the ability of the petroleum refining system to adapt to these changes in its economic environment. Similar trends towards induced innovation directed towards improving the efficiency of utilisation were observed in other technologies, for example in motor cars (see Jaffe et al, 2001).

In summary, the general trend followed by oil refining technology can be described as a move away from physical separation technologies and towards technologies aimed at changing the chemical composition of the different fractions. In order to follow demand trends for the products of the oil industry, physical separation techniques were not enough and had to be supplemented by other techniques that could change composition beyond what was obtainable by means of physical separation alone.

The early changes in demand that contributed to the emergence of new refining technologies were due to the development of a number of technologies that used petroleum products as inputs. Examples of these technologies are most transport technologies (motor cars, trucks, trains, aircraft etc.) and chemical technology after the 1930s. In the early XXth century these technologies were either new or they were using a different set of inputs (coal based). Their markets kept increasing until the 1970s, thus providing a stable pattern of growth for the petroleum refining industry. In the same period the supply of oil increased without any substantial bottlenecks while the price of oil fell in real terms. In the period from 1932 to 1978 the selection environment for petroleum refining was fairly stable. An important perturbation took place in the early 1970s, resulting in a very rapid rise of oil price. In this changed selection environment the main goal of petroleum using sectors became to increase the efficiency of utilisation of petroleum products. This perturbation was accompanied by an increasing concern with the environmental impact of petroleum using technologies. We have already seen that process variety fell during the stable 1932-1978 period and that it started oscillating between a sharp increases and a fall after 1978, leading quite likely to a slowly rising trend in the most recent period 1992-1998. Thus there seems to be a correlation between the nature of the selection environment and the trends in process variety.

Summarizing this section, the changes in variety we observed are related to two types of factors: first, new technologies have been created in order to supply new fractions corresponding to demand trends; second, the variance in performance of the new technologies became gradually narrower, giving rise to the observed fall in variety of process characteristics. The first trend took place by means of a shift away from physical separation techniques and towards techniques aimed at changing the chemical composition of the fractions. Comparing the two trends we notice a divergence between the growing variety of oil refining observed in Fig. 3 and the falling variety of its process characteristics. This apparent contradiction can be explained by the different methods and data used to construct Fig 3 and to perform the calculations of variety. As we already pointed out, while the 
method used to construct Fig. 3 tends to overstate variety growth the approach used for the calculations tends to understate variety growth. In turn, these two opposite biases follow from the degree of radicalness assumed for the innovations in petroleum refining. Fig. 3 tends to overstate the radical character of innovations in this technology while the calculations stress more heir incremental nature. Part of this contradiction follows from the fact that new technologies, while providing the fractions required by present demand, share common parts or modules with pre-existing technologies. Radical innovations, even when they are present, only contribute to shift gradually the service characteristics of the technology.

The pattern of stable growth in output combined with increasing output differentiation lasted until 1978. In the subsequent period a shock in the selection environment was accompanied by an interruption of the previous trend, leading to a rapid increase and successive fall in variety between 1978 and 1992. The present trend after 1992 seems to be towards slowly increasing process variety. Thus, demand patterns, or more generally the nature of the selection environment have clearly been very important determinants of the evolution of petroleum refining.

\section{2) SUMMARY AND CONCLUSIONS}

In this paper we analysed the evolution of variety in petroleum refining technologies during the period 19321992. To do this we used a number of tools. We measured variety by means of Weitzman's function. Also, we plotted the chronological tree defined by the times at which different refining technologies appeared. In the calculation of Weitzman's function we had to solve a number of problems, such as the reduction in size of the sample of observations in order to reduce computing times, which we achieved by introducing a classification method. The results obtained by the different methods do not coincide. The genealogical tree seems to indicate a growing variety, while the calculations based on Weitzman distance seem to indicate a variety falling for most of the time and rising only in recent periods. The reason for these differences can be found in (i) a different bias of the methods used, and, (ii) the different extent to which the methods reflect process and output variety.

According to the calculations based on Weitzman distances, the 66 years of the period studied can be separated into the two sub-periods 1932-1978 and 1978-1992. In the former process variety falls over time. Variety increases sharply in the period 1978-1986 and, possibly, for 1992-1998. These changes in variety cannot be interpreted as the result of a dominant design, since the products of this industry are as design free as possible. However, elements of design may play an important role in the mechanical part of refining equipment. Thus, the general decreasing trend in variety for the period points towards a form of standardization of the new technologies introduced, which could have been achieved by combining common sets of modules. New oil refining technologies introduced to respond to emerging demand trends could have shared most of the principles and techniques with pre-existing technologies. In other words, they are incremental rather than radical innovations, and so determine decreasing marginal improvements in the performance of the industry. The radical nature of some of the innovations introduced (e.g. catalytic cracking) does not substantially change the situation, since these innovations are combined with modules common to previous technologies.

Our limited ability to distinguish radical from incremental innovations is responsible for the apparent contradiction observed between the genealogical tree (Fig. 3), which shows an increasing number of branches, and the results of our calculations. While the former seems to imply an increasing variety the latter tells us that variety has been falling most of the time. This difference is due to the fact that in the construction of the genealogical tree all new processes were considered distinguishable, thus exaggerating the degree of radicalness of the changes. On the contrary, the data used in the calculations were based on the same set of continuous characteristics for all the processes, thus reducing the extent of their differentiation. In other words, the procedure used in the calculations had a bias towards reducing variety while the one used to construct the genealogical tree was biased towards overestimating variety. We could then say that the real change in variety lies in between those detected by the calculations and by the genealogical tree, but we are inclined to give a greater weight to the calculations for being based on a more complete set of data and on a more objective methodology.

The evolution of petroleum refining bears a very close relationship to that of demand or, more generally, of the selection environment for this technology. Early trends in petroleum refining can be explained as an increasing differentiation of output in order to supply an increasingly differentiated demand. The closeness of this relationship is confirmed by the trend in the period after 1978, during which a shock to the selection environment induces changes in refining technology. Of course, this explanation would need to be confirmed by a quantitative study including all the variables that can be considered potential determinants of variety. We do not have this information available, but we consider that the oil price shock which occurred in the mid 1970s was by far the 
most important change affecting the petroleum refining industry and that any other change can be neglected wit respect to it in a first approximation.

When we say that the evolution of petroleum refining bears a very close relationship to that of demand we do not think that demand is the cause of the evolution of this industry. The situation can be better represented as the coevolution of demand, or selection environment, and technology. The inducement of technological change by demand cannot be interpreted as a passive response of the technology to changes in the selection environment, in the way in which a change of techniques was expected to take place in the production function. On the contrary, the adaptation of technologies, which sometimes occurs by means of radical innovations, requires the allocation of resources to search activities and leads to partly unpredictable outcomes. Furthermore, the adaptation of technologies modifies the selection environment. Thus the co-evolution of technology and demand seems a much more appropriate representation of the evolution of petroleum refining.

\section{REFERENCES}

Absi-Halabi M., Stanislaus A., Qabazard H., 1997, Trends in catalysis research to meet future refining needs, Hydrocarbon Processing, February 1997, p.45- 55

American Petroleum Institute, 1959, Petroleum Facts and Figures, Centennial Edition

Bel F., Bourgeois B., Innovation and direction persistence within an industry : the refining process case, In Saviotti P.P. (Ed), Applied Evolutionary Economics: New empirical methods and simulation techniques, London : Edward Elgar, (2003).

Bils M., Klenow P.J., The acceleration in variety growth, AEA Papers and Proceedings, Vol $91 \mathrm{~N}^{\circ} 2$ (2001) 274-280.

Bourgeois B. - " Les carburants reformulés : une dynamique d'innovations de modernisation écologique ", p. 311 338 et " L'exploration-production pétrolière : discontinuité technologique et fertilisation par les technologies de l'information et de la communication ", p. 369-394.- In : Energie et changement technologique. Une approche évolutionniste.- Paris : Economica, 2000, 490 p.

Château B., Lapillonnne B., 1999, La consommation mondiale d'énergie 1950-2000 : Tendances Lourdes, Ruptures et Messages pour l'Avenir, Revue de l'Energie, 50 ans, n 509, Septembre 1999, pp.489-496

A.K. Dixit, J.E. Stiglitz, Monopolistic competition and optimum product diversity, American Economic Review, Vol. 67 (1977) 297-308.

EIA, 1990, The U.S. Petroleum Refining Industry in the 1980's, DOE/EIA-0536, 92 pp.

Enos J.L., (2002), Technical progress and profits : process improvements in petroleum refining, Oxford, Oxford University Press.

Freeman C. and Soete L., The Economics of Industrial innovation, MIT press, Third edition, Cambridge, 1997, 470 pages.

Frenken K., Saviotti P.P., Trommetter M., "Variety and niche creation in aircraft, helicopters, motorcycles and microcomputers", Research Policy, No. 28, (1999) pp469-488.

Funke M., Ruhwedel R., Product variety and economic growth: Empirical evidence for the OECD countries, IMF Staff papers, Vol 48, N², (2001a)

Funke M., Ruhwedel R., Export variety and export performance: empirical evidence from East Asia, Journal of Asian Economics, Vol 12 (2001b) 493-505.

Gibbons M., Coombs R., Saviotti P.P., Stubbs P. Innovation and Technical Change, a case study of the UK tractor industry 1957-77, Research Policy, 11 (1982), 289-310.

Heinrich G, Introduction au raffinage (1994), chap. 10, pp 373-453, Technip, Paris

Jaffe A.B., Newell R.G., Stavins R.N., (2001) Technological change and the environment, in Mäler Vincent G., (Eds) The Handbook of Environmental Economics, Amsterdam, North Holland.

Kemp R., Soete L., 1992, The greening of technological progress- An evolutionary perspective, Futures, June 1992, pp.437-459

Kuznets S., Economic Growth and Structure, Norton, New York (1965).

Lancaster K.J., A new approach to consumer theory, Journal of Political Economy 14 (1966) pp 133-156

Lancaster K.J., Socially optimal product differentiation, American Economic Review 65 (1975) pp567-585

May R.M., Stability and Complexity in Model Ecosystems, Princeton Univ. Press, Princeton (1973).

Nelson R.R., Winter S.G. An Evolutionary Theory of Economic Change, Cambridge MA, Harvard University Press (1982)

Oil \& Gas Journal, Refining milestones, Petroleum in the 21st Century,p.116 (Dec. 13 1999).

Oil and Gas Journal , Refining Catalyst demand, (Oct.9, 2000), p.6

Petroleum Refiner, 1949, 1949 Process Issue, A Foreword, Petroleum Refiner, September 1949, p.113

Romer P., Endogenous technical progress, Journal of Political Economy 98 (1990) pp 71-102 
Romer P., Growth based on increasing returns due to specialization, American Economic Review 77 (1987) pp562-565.

Saviotti P.P., Technological evolution, variety and the economy, Edward Elgar, Cheltenham (1996).

Saviotti P.P., The measurement of changes in technological output, in van Raan A. (Ed) Handbook of quantitative

studies of science and technology North-Holland, Amsterdam, (1988) pp.555-601.

Saviotti P.P., An approach to the measurement of technology based on the hedonic price method and related methods" Technological Forecasting and Social Change, 27, (1985) 309-334, reprinted in H. Grupp (ed.) Problems of measuring technological change, Koln, Verlag TUV Rheinland (1986).

Saviotti P.P., The role of variety in economic and technological development, in: Saviotti P.P.,

Metcalfe J.S. (Eds), Evolutionary Theories of Economic and Technological Change Harwood Academic Publishers, Chur (1991).

Saviotti P.P., Bowman A., Indicators of Output of Technology, some general considerations and an application to the Evolution of Aircraft Technology", in Science and Technology Policy in the 1980s and beyond, (M. Gibbons, P. Gummett, eds.), London: Longman (1984).

Saviotti P.P., Mani G., Competition, variety and technological evolution: a replicator dynamics model, Journal of Evolutionary Economics 5 (1995) pp369-392

Saviotti P.P., Metcalfe J.S., A theoretical approach to the construction of technological output indicators, Research Policy 13, (1984) pp141-151

P.P. Saviotti, A. Trickett, The evolution of helicopter technology: 1940-1986, Economics of Innovation and New Technology, Vol. 2 (1992) 111-130.

Simon H.A., The sciences of the artificial, MIT press, Cambridge, MA (1969).

US Dpt Of Energy, Petroleum Supply Annuals, Energy Information Administration ed., Washington, (2001), 165 pages

Utterback, J.M., Abernathy, W.J., A dynamic model of product and process innovation, Omega, Vol. 3, (1975) 639-656.

Utterback J.M., Suarez F.F., Innovation, competition and industry structure, Research Policy, Vol 22, (1993) pp. $1-21$.

Weitzman M. L., On diversity, Quarterly Journalof Economics, Vol. 107, (1992), pp. 363-406 


\section{APPENDIX 1}

TableA1: process variables for petroleum refining for 1932

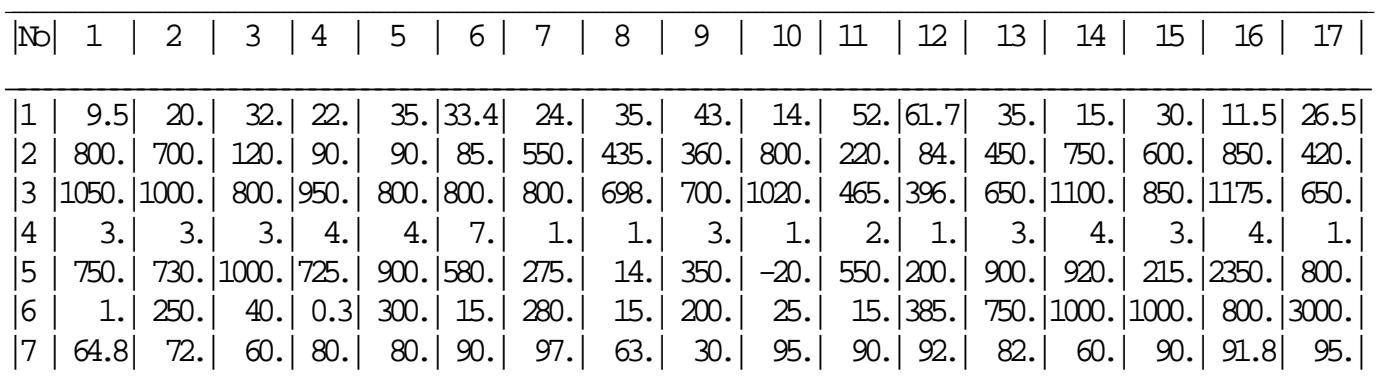

TableA2: process variables for petroleum refining for1966

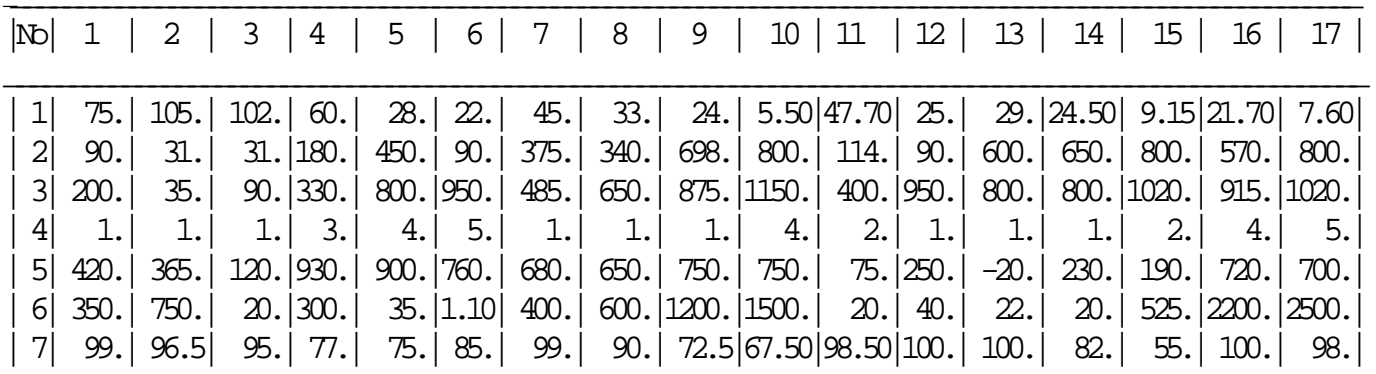

TableA3: process variables for petroleum refining for1992

\begin{tabular}{l|l|l|l|l|l|l|l|l|l|l|l|l|l|l|l|l|l|l|}
\hline $\mathrm{Nb}$ & 1 & 2 & 3 & 4 & 5 & 6 & 7 & 8 & 9 & 10 & 11 & 12 & 13 & 14 & 15 & 16 & 17 \\
\hline
\end{tabular}

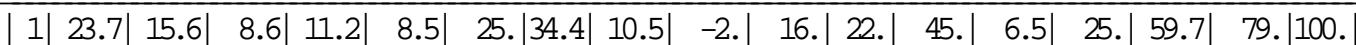

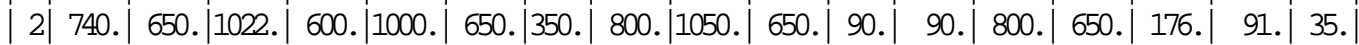

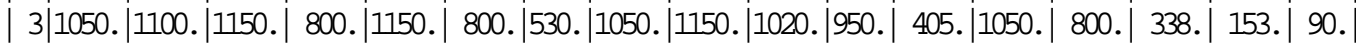

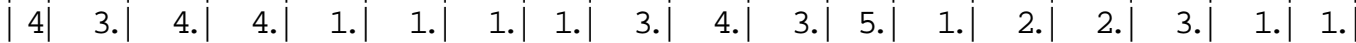

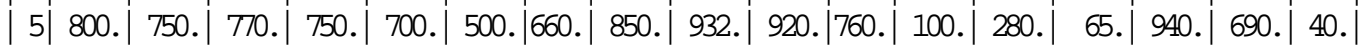

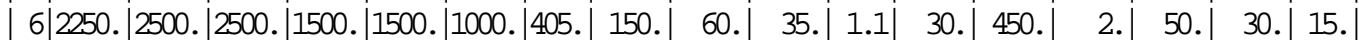
| 7| 93.| 95.| 70.| 95.| 89.| 95.|87.5| 35.| 50.| 95.| 85.| 65.| 50.| 65.| 86.| 98.|160.|

Table A4 Variables describing each oil refining process in the database :

- gravity [var.1];

- minimum temperature [var.2] and maximum temperature [var.3] of feedstock;

- number of products [var.4];

- operating conditions as process temperature [var.5];

- pressure [var.6];

- efficiency [var.7].

Table A5 Time distribution of the introduction of new processes in oil refining:

- 1932 : 48 process units;

- 1947 : 80 process units;

- 1958 : 79 process units;

- 1966 : 84 process units;

- 1972 : 96 process units;

- 1978 : 94 process units; 
- 1986 : 96 process units;

- 1992 : 56 process units;

- 1998 : 73 process units. 


\section{Appendix 2.}

An example of the calculation of Weitzman's distance, including maximum likelihood trees.

Consider 9 observations of refinery processing on 3 variables that are given on Table A6.

Table A6: Data for 9 refinery processes.

\begin{tabular}{|l|c|c|c|}
\hline Observations & Gravity ( $\left.{ }^{\circ} \mathbf{A P I}\right)$ & Products & Temperature(F) \\
\hline Observation 1 & 85 & 1 & 40 \\
\hline Observation 2 & 90 & 1 & 120 \\
\hline Observation 3 & 53 & 1 & 700 \\
\hline Observation 4 & 50 & 2 & 800 \\
\hline Observation 5 & 26.5 & 3 & 900 \\
\hline Observation 6 & 52 & 4 & 940 \\
\hline Observation 7 & 31 & 5 & 760 \\
\hline Observation 8 & 10.5 & 1000 \\
\hline Observation 9 & 22 & 1 & 900 \\
\hline
\end{tabular}

After having transformed Table A6 into a normalized matrix, we can determine the Euclidean distance, which is given, for the 9 observations, in Table A7.

Table A7: Euclidean distance matrix

\begin{tabular}{|lllllllllll|}
\hline Obs. & 1: & 0.00 & & & & & & & & \\
Obs. & $2:$ & 0.26 & 0.00 & & & & & & \\
Obs. & $3:$ & 0.69 & 0.80 & 0.00 & & & & & \\
Obs. & $4:$ & 1.14 & 1.39 & 0.96 & 0.00 & & & & \\
Obs. & $5:$ & 1.62 & 1.85 & 1.26 & 0.53 & 0.00 & & & & \\
Obs. & $6:$ & 1.60 & 1.85 & 1.53 & 0.69 & 0.80 & 0.00 & & & \\
Obs. & $7:$ & 1.91 & 2.13 & 1.67 & 1.08 & 0.97 & 0.67 & 0.00 & & \\
Obs. & $8:$ & 2.48 & 2.67 & 2.17 & 1.70 & 1.48 & 1.30 & 0.65 & 0.00 & \\
Obs. & $9:$ & 2.52 & 2.67 & 2.27 & 1.99 & 1.90 & 1.61 & 0.99 & 0.61 & 0.00 \\
\hline
\end{tabular}

As it can be seen from Table A7, the number of subgroups that can be formed starting from the observations of Table A6 varies according to the distance used. If we are only concerned with two subgroups, distance should be greater than 1.8. If the number of groups increases gradually, the distance will be below 1.8. The distance represented on the vertical axis in Fig. A1 can thus be interpreted as the resolution of our map of the technology: the smaller the distance, the finer the details we can 'see'. Both Weitzman's measure of diversity and the maximum likelihood trees that are calculated to obtain it, depend on the resolution adopted. Figs A2 show the influence of resolution on the maximum likelihood trees. 


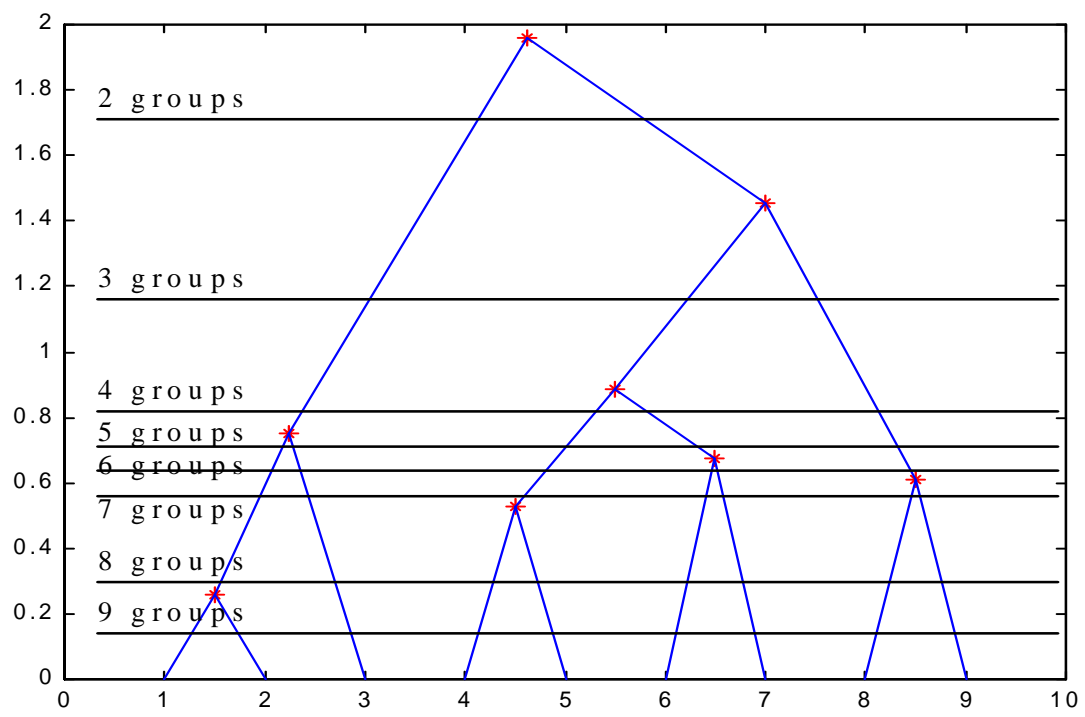

Fig. A1. Tree obtained by the classification method

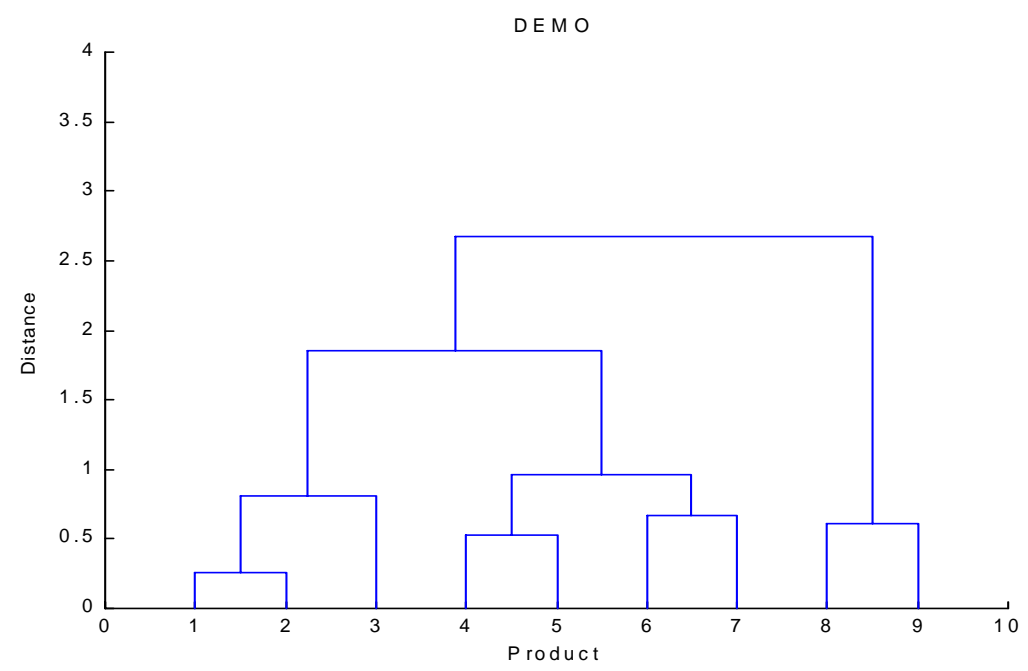

Fig. A2. Maximum likelihood tree for 9 groups

From the distance matrix in Table A7, a tree obtained by average distance method as shown in Fig. A1. The maximum likelihood tree for 9 groups obtained by Weitzman method is shown in Fig A2. The maximum likelihood determined by Weitzman's measure of diversity:

$\mathrm{V}(\mathrm{S})=0.255+0.530+0.611+0.674+0.804+0.967+1.853+2.671=8.364$ 